\title{
Evaluation of the coaching effectiveness as an instrument for motivating company's employees
}

\author{
Anna Minnullina ${ }^{1, *}$, Rais Abdrazakov ${ }^{2}$ and Petr Graboviy ${ }^{3}$ \\ ${ }^{1}$ Tyumen Industrial University, Volodarskogo St., 38, Tyumen, 625000, Russia \\ ${ }^{2}$ Northern Trans-Ural State Agricultural University, Respublika St., 7, Tyumen, 625003, Russia \\ ${ }^{3}$ Moscow State University of Civil Engineering, Yaroslavskoe shosse, 26, Moscow, 129337, Russia
}

\begin{abstract}
The paper proposes a technique for evaluating the motivation of the company's employees using the "balance wheel" tool. The methods involve making a score of motivational factors' set and a wheel of motivational balance. To confirm the effectiveness of its implementation, the coaching was approbated at the municipal autonomous institution "Fortuna" for 6 months. The results were analyzed before and after the implementation of the project activities, which clearly reflected the positive dynamics of the coaching influence on the level of satisfaction of the company's employees with their work.
\end{abstract}

\section{Introduction}

Given the conditions when there is a qualitative complication of management due to the fact that the role of socio-psychological technologies increases, there is a requirement to deepen the level of professionalism and the knowledge of a manager's specialist field. Coaching is a tool that allows not only to combine different techniques, but also to discover new opportunities for development. Technology of coaching has a positive impact on both the efficiency of individual employees and on the activities of the whole organization.

In general, an employee's productivity can be represented as a combination of two important components - the motivation of a person to work and the achievement of the organization's goals and his or her skills, that is, his or her ability to perform professional duties. The higher the employee is in the hierarchy of the organization, the stronger his efficiency is affected by motivation and general management skills. To strengthen the motivation and form the desired successful behavior, it is required to have close human contact, experimentation and real-time feedback. Coaching as a method of management and motivation fully ensures the provision of these conditions.

According to numerous studies, under the modern market conditions, coaching is rapidly developing. This is confirmed by the willingness of many Russian companies to consider and implement coaching as a management tool that enhances the efficiency of employees and the company's competitiveness.

In the field of coaching research, it is necessary to highlight the works of T. Gallwey, Thomas J. Leonard, J. Whitmore, D. Goleman, S. Freud, C. Jung, A. Adler, C. Rogers, A.

\footnotetext{
*Corresponding author: minnullinaay@yandex.ru
} 
Maslow, W. Stern, L. Thurstone, J. Guilford, H. Gardner, M. Perrez, U. Baumann, V.P. Pugachev, A.I. Ageev, B.V.Kuroedov, J. M. Ivantsevich, A.V.Kopytova, A.A. Lobanov, E. Parslow, M. Ray, S. A. Rogachev, A.D. Savkin, M.A. Danilov, J. Harris and etc. [1-19] In these works, coaching is considered for the most part as an effective management technology, talent disclosure and an instrument for achieving goals, but the question of implementing coaching as a technology for personnel motivation has not been fully studied.

Coaching can be viewed from different perspectives: as art, function, process, management style, personality development method, communication and management method.

In recent years, coaching has become increasingly popular as a management style, taking into account that the coaching technologies are part of a manager's day-to-day activities. This permits to create an environment, in which the maximum potential of the staff can be fulfilled with growing internal motivation of the staff to work.

There are many ways to improve the staff efficiency. To do this, one may choose different ways and methods of improvement, but, as it is widely known, innovations in the organization are often accompanied by fairly large expenditures, but no guarantees are provided. Therefore, in the context of the crisis trends and the limitation of both material and time resources, it is important to find the directions for achieving the greatest results in the shortest time with the optimal costs.

To solve this problem, it is necessary to consider what determines the effectiveness of the employees' activities, as well as to identify areas for improvement of this activity.

\section{Methods}

Evaluation of the effectiveness of tools' implementation for motivating employees of the company can be performed with the help of the coaching tool called "balance wheel". Moreover, when elaborating the author's methodology, the studies were based on the works of R. Matthews and B.V. Kuroedov (strategic matrix), E.I. Komarov (method of determining the motivational balance) and N.A. Zhdankin (technique of enneagram of staff motivation) $[2,6,7]$.

The main motivating factors that lead to meeting the expectations, are as follows:

1) professional and job growth;

2) achievement of goals;

3) high degree of independence and responsibility;

4) opportunity to succeed and be recognized;

5) opportunity for personal fulfillment;

6) interesting content of the work;

7) style of the higher management;

8) relations with colleagues.

Each of the above-mentioned factors is evaluated by a company employee on a 10-point scale, in accordance with the level of motivational perception (Table 1).

Table 1. Scale of motivational factors' evaluation.

\begin{tabular}{|l|c|c|c|}
\hline \multirow{2}{*}{ Level of motivation } & \multicolumn{3}{c|}{ Score of motivation factor } \\
\cline { 2 - 4 } & Below average & Average & Above average \\
\hline High & 8 & 9 & 10 \\
\hline Average & 5 & 6 & 7 \\
\hline Low & 2 & 3 & 4 \\
\hline Lack of motivation & 1 & 1 & 1 \\
\hline
\end{tabular}

Evaluation of the motivational perception is divided into three levels (high, average and low, and each level of motivational perception is also divided into three levels depending on 
the scores (below average, average and above the average). In case of the lack of motivation, the factor is assigned a value of 1 .

The employee of the company evaluates the motivational factor in accordance with her or her expectations and preferences in specific conditions, created by a particular company.

Based on the results of the interview, an individual motivation score is calculated by the following formula (1) [6]:

$$
P M=\sum_{i=1}^{n} C_{i}
$$

$C_{i}$ - individual evaluation of a particular motivational factor $(i) ; n$ - the total amount of the assessed motivational factors.

To conduct the analysis of the group motivation (section and department), it is recommended to perform a factor analysis, that is the analysis of the group level of motivation for each separate factor. Primarily, the assessments of employee's stability and his or her certainty in career development are collected, then the average is derived, after that according to the clearness of a target, the average is also derived and etc.

Thus, the group motivation score (PM) is defined as the sum of the average estimates of the people, who make up the tested team, for each factor of motivation, according to the formula (2):

$$
P M=\frac{\sum_{j=1}^{m} C_{1}}{m}+\frac{\sum_{j=1}^{m} C_{2}}{m}+\cdots+\frac{\sum_{j=1}^{m} C_{n}}{m}
$$

$C_{i}$ - individual evaluation of a particular motivational factor $(i) ; n-$ the total amount of the assessed motivational factors; $m$ - number of employees, who participate in the evaluation.

If the group's estimates of certain motivational factors are extremely low, then this will be an objective view on the problem, showing that this factor is equally perceived not only by a specific employee of the company, but also by the whole group (section and department).

To assess the motivational factors, it is recommended to create a special map, developed on the basis of N.A. Zhdankin's research [2]. The map is created to assess individual and group motivation of the company's employees (Table 2).

Based on the results of proposed map's registration, the overall level of employee's motivation is determined as the sum of scores according to all motivational factors. To determine the level of anti-motivation, the value of the overall level of motivation is subtracted from the maximum possible one ( $m \times n=80)$.

The following formula is used to assess the motivational balance (3):

$$
M B=\frac{\sum_{j=1}^{m} C_{i}}{\sum_{j=1}^{m} C_{n-i}}
$$

The motivational balance can be calculated for the evaluation of the individual level of motivation, as well as the group one.

The main conditions for the implementation of the motivational balance are as follows:

1 . The ratio of the overall level of motivation to the overall level of anti-motivation should be equal to 1 or more.

2. When creating a map, the "motivation" sector should be fully captured.

3. All values of the motivational factors' score should be approximately equal between.

To visualize the motivational balance, the "Wheel of motivational balance" is presented in the form of a radar chart divided into 8 sectors, and each sector displays a separate motivation factor (Figure 1). 
Table 2. Map of assessing individual/group motivation of company's employees.

\begin{tabular}{|l|l|l|l|l|l|l|l|l|l|l|l|}
\hline \multicolumn{1}{|c|}{ Motivational factor } & \multicolumn{7}{|c|}{ Assessment of motivation, score } & Balance \\
\cline { 2 - 11 } & 1 & 2 & 3 & 4 & 5 & 6 & 7 & 8 & 9 & 10 & \\
\hline $\begin{array}{l}\text { Professional and job } \\
\text { growth }\end{array}$ & & & & & & & & & & & \\
\hline Achievement of goals & & & & & & & & & & & \\
\hline $\begin{array}{l}\text { High degree of } \\
\text { independence and } \\
\text { responsibility }\end{array}$ & & & & & & & & & & & \\
\hline $\begin{array}{l}\text { Opportunity to succeed } \\
\text { and be recognized }\end{array}$ & & & & & & & & & & & \\
\hline $\begin{array}{l}\text { Opportunity for personal } \\
\text { fulfillment }\end{array}$ & & & & & & & & & & & \\
\hline $\begin{array}{l}\text { Interesting content of the } \\
\text { work }\end{array}$ & & & & & & & & & & & \\
\hline $\begin{array}{l}\text { Style of the higher } \\
\text { management }\end{array}$ & & & & & & & & & & \\
\hline $\begin{array}{l}\text { Relations with } \\
\text { colleagues }\end{array}$ & & & & & & & & & & & \\
\hline Total & & & & & & & & & & \\
\hline
\end{tabular}

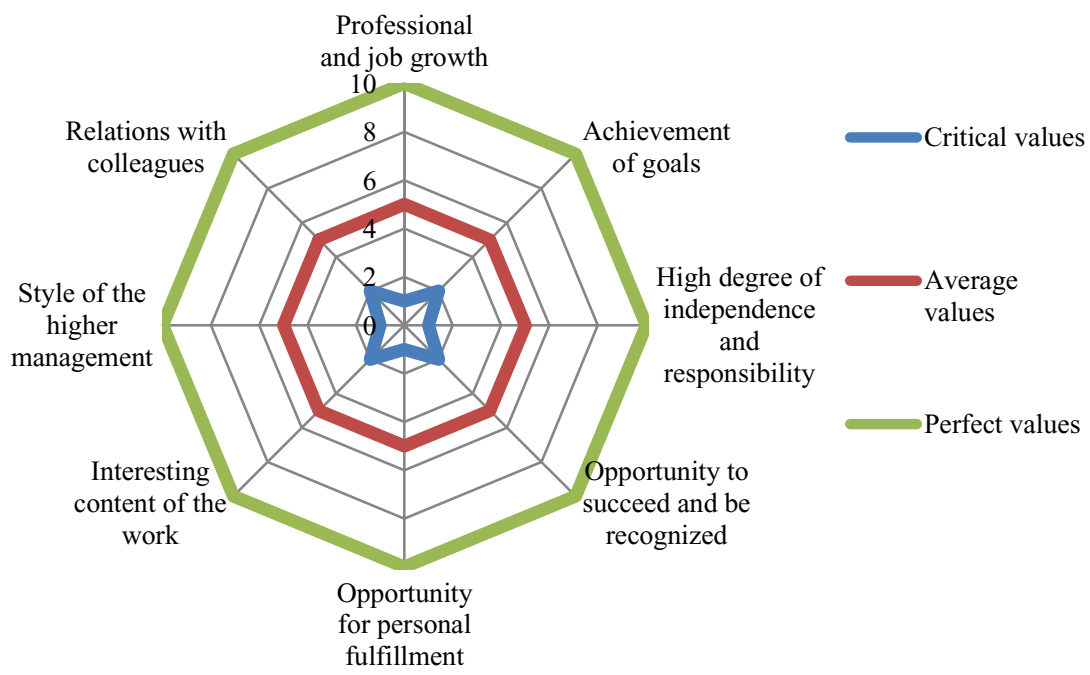

Fig. 1. Wheel of motivational balance.

\section{Results}

To approbate the proposed methodology, an analysis was conducted on the motivation of the administrative and management staff of the municipal autonomous institution of a supplementary education center for children and youth "Fortuna" in Tyumen. The main goal of the establishment "Fortuna" is to provide supplementary education for children in the sphere of youth policy, as well as to organize comprehensive and smart leisure. It is aimed at the upbringing and development of a socially active, educated, morally and physically healthy person. The establishment "Fortuna" has nine buildings in the city of Tyumen, at each of which the pedagogical activity is performed. As of 2017, in accordance with the municipal assignment, the number of service recipients of "Fortuna" was 1700 people in total. 
Within the framework of the current system of the motivation of the establishment's employees, the coaching has been implemented to develop the skills, which are expressed to a lesser degree, to succeed in overcoming crises at the organization and to provide education of future leaders within the organization.

To assess the effectiveness of the coaching technology's implementation at the organization "Fortuna", individual and group motivation of employees was assessed twice: before the implementation of the coaching technology in the management and 6 months after it was held.

The survey was conducted to evaluate the opinion of "Fortuna" employees on the motivational factors. The main purpose of the survey was to identify factors of employees' satisfaction with their work. In the questionnaire, the employee was asked to assess his or her level of satisfaction with various factors and conditions, related to work.

To assess the motivational level, employees from the supervisory board (4 employees), the teaching staff (9 employees) and the administrative and managerial staff ( 3 employees) of the "Fortuna" organization were involved. The results of the individual evaluation prior to the implementation of the coaching technology were processed and summarized in the assessment of the group motivation of the "Fortuna" staff. Table 3 shows a map of the assessment of the employees' group motivation, where SB is an assessment of the motivational factors of the supervisory board's employees, TS is an assessment of the motivational factors of the teaching staff, and AMC is an assessment of the motivational factors of administrative and managerial personnel.

Table 3. Map of assessment of the employees' group motivation at the municipal autonomous institution "Fortuna" before the coaching technology was introduced.

\begin{tabular}{|l|c|c|c|c|}
\hline \multirow{2}{*}{ Motivational factor } & \multicolumn{3}{c|}{$\begin{array}{c}\text { Group motivational } \\
\text { assessment, score }\end{array}$} & \multirow{2}{*}{$\begin{array}{c}\text { Total } \\
\text { average } \\
\text { assessment }\end{array}$} \\
\cline { 2 - 4 } & SB & TS & AMC & \\
\hline Professional and job growth & 5.9 & 4.3 & 3.1 & 4.4 \\
\hline Achievement of goals & 6.3 & 5.7 & 4.9 & 5.6 \\
\hline High degree of independence and responsibility & 5.8 & 3.8 & 2.8 & 4.1 \\
\hline Opportunity to succeed and be recognized & 5.2 & 5.1 & 4.7 & 5.0 \\
\hline Opportunity for personal fulfillment & 6.1 & 4.1 & 2.5 & 4.2 \\
\hline Interesting content of the work & 5.4 & 4.6 & 3.4 & 4.5 \\
\hline Style of the higher management & 5.7 & 4.3 & 3.8 & 4.6 \\
\hline Relations with colleagues & 6.5 & 5.2 & 4.0 & 5.2 \\
\hline Total & 46.9 & 37.1 & 29.2 & 37.7 \\
\hline
\end{tabular}

The map (Table 3) clearly demonstrates that in the "Supervisory Board" (SB) group, the highest evaluation was given to the factors of the relations with colleagues, the achievement of goals and the opportunity for personal fulfillment. The lower evaluation was given to the opportunity to succeed and be recognized. The overall motivational level in this employees' group is 46.9, and accordingly, the level of anti-motivation is 33.1. As a result, the motivational balance is $\mathrm{MB}=46.9 / 33.1=1.42$. In this category, the level of motivation exceeds the one of anti-motivation, which, nevertheless, indicates an insufficient level of staff motivation.

Group motivational assessment "Teaching staff" (TS) shows that the highest score was obtained by the factors of achievement of goals and relations with colleagues, and the lowest one is the factor of independence and responsibility. The overall level of motivation at this organization is 37.1. Subtracting this value from the maximum possible value (80), we get the anti-motivation level, amounting to 42.9. And then the motivational level is $M B=37.1$ / $42.9=0.86$. In this category, anti-motivation exceeds motivation, indicating the predominance of demotivating factors and extremely low level of motivation.

The evaluation of the motivational factors by the "Administrative and Managerial 
Personnel" group (AMP) shows that the highest evaluation was given to the factors of achievement of the goals and the opportunity to succeed and be recognized, and the lowest one - the opportunity for personal fulfillment and the factor of independence and responsibility. The overall level of motivation in this group is 29.2. Subtracting this value from the maximum possible value (80), we get the anti-motivation level of 50.8. Accordingly, the motivational balance is $\mathrm{MB}=29.2 / 50.8=0.57$. In this group of employees, the antimotivation level is almost 2 times higher than the motivational one, which indicates a significant predominance of demotivating factors and almost complete absence of nonmaterial motivation of employees. It can be noted that this group of employees mainly consists of employees of retirement age, creating excessive bureaucratization of all communications and procedures and blocking opportunities for initiatives and development.

Visual presentation of the data on the satisfaction of the study groups of personnel before the implementation of project activities is shown in Figure 2.

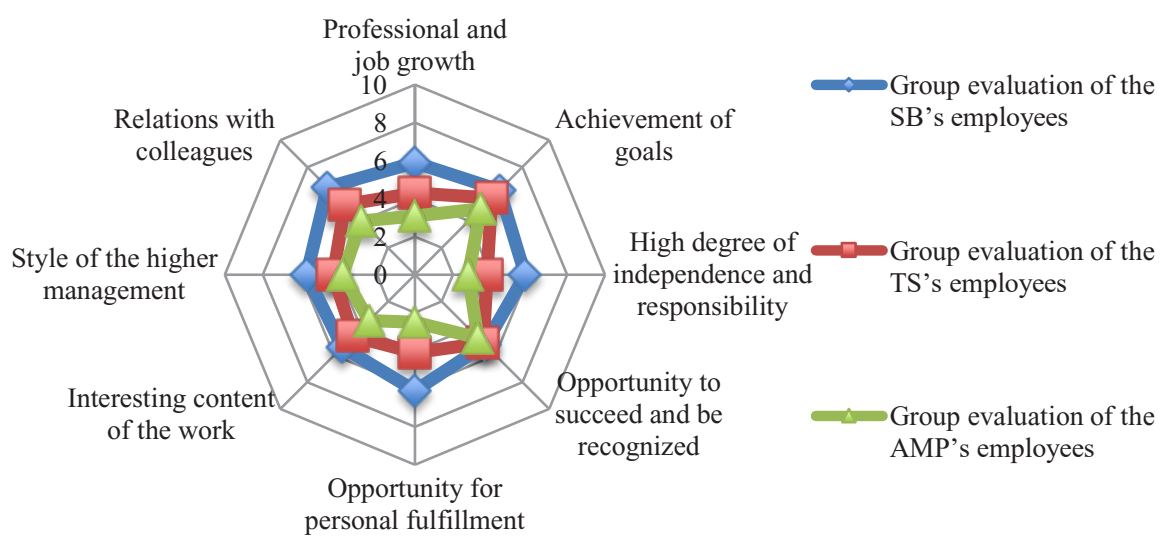

Fig. 2. Wheel of motivational balance of the "Fortuna" employees before the implementation of the coaching technology.

The wheel of the motivational balance of "Fortuna" employees' groups showed that the lacking factors are the opportunity for personal fulfillment and interesting content of the performed work.

Six months after the implementation of the coaching technology into the motivational program of the municipal autonomous institution "Fortuna", the employees have questioned again in similar groups.

The results of the assessment of non-material motivation factors are demonstrated in Table 4.

It can be seen from the analysis that all factors' values were improved: the factor of professional and job growth increased by 0.7 points; the assessment of the significance of achieving the goals increased by 1 ; independence and responsibility - by 1.5 ; opportunity to succeed and be recognized - by 1.2; opportunity for personal fulfillment - by 1.5; the content of the work performed is 1.4; style of the higher management - by 1.5; and relations with colleagues - by 1.8 .

There is a significant increase in the following factors: relations with colleagues, opportunity for personal fulfillment, independence and responsibility. This shows that the implementation of the coaching approach at the organization has a significant impact on the motivational factors. Accordingly, increasing the employees' satisfaction, it is possible to have a positive influence on the employees' motivation to work in general. 
Table 4. Map of assessing group motivation of the employees of the Municipal Autonomous Institution "Fortuna", 6 months since the introduction of the coaching technology.

\begin{tabular}{|l|c|c|c|c|c|}
\hline \multirow{2}{*}{ Motivational factor } & \multicolumn{3}{c|}{$\begin{array}{c}\text { Group motivational } \\
\text { assessment, score }\end{array}$} & \multicolumn{2}{c|}{$\begin{array}{c}\text { Total average } \\
\text { assessment }\end{array}$} \\
\cline { 2 - 6 } & SB & TS & AMP & $\begin{array}{c}\text { After the } \\
\text { coaching }\end{array}$ & $\begin{array}{c}\text { Before the } \\
\text { coaching }\end{array}$ \\
\hline Professional and job growth & 6.5 & 5.2 & 3.6 & $\mathbf{5 . 1}$ & 4.4 \\
\hline Achievement of goals & 7.9 & 6.5 & 5.3 & $\mathbf{6 . 6}$ & 5.6 \\
\hline $\begin{array}{l}\text { High degree of independence and } \\
\text { responsibility }\end{array}$ & 7.5 & 5.1 & 4.2 & $\mathbf{5 . 6}$ & 4.1 \\
\hline $\begin{array}{l}\text { Opportunity to succeed and be } \\
\text { recognized }\end{array}$ & 6.8 & 6.4 & 5.5 & $\mathbf{6 . 2}$ & 5.0 \\
\hline Opportunity for personal fulfillment & 7.5 & 6,1 & 3.4 & $\mathbf{5 . 7}$ & 4.2 \\
\hline Interesting content of the work & 7.2 & 6.7 & 3.9 & $\mathbf{5 . 9}$ & 4.5 \\
\hline Style of the higher management & 7.9 & 6.1 & 4.3 & $\mathbf{6 . 1}$ & 4.6 \\
\hline Relations with colleagues & 8.9 & 6.9 & 5.2 & $\mathbf{7 . 0}$ & 5.2 \\
\hline Total & 60.2 & 49.0 & 35.4 & $\mathbf{4 8 . 2}$ & 37.7 \\
\hline
\end{tabular}

The wheel of the motivational balance of "Fortuna" employees' groups after the implementation of coaching technology is presented in Figure 3.

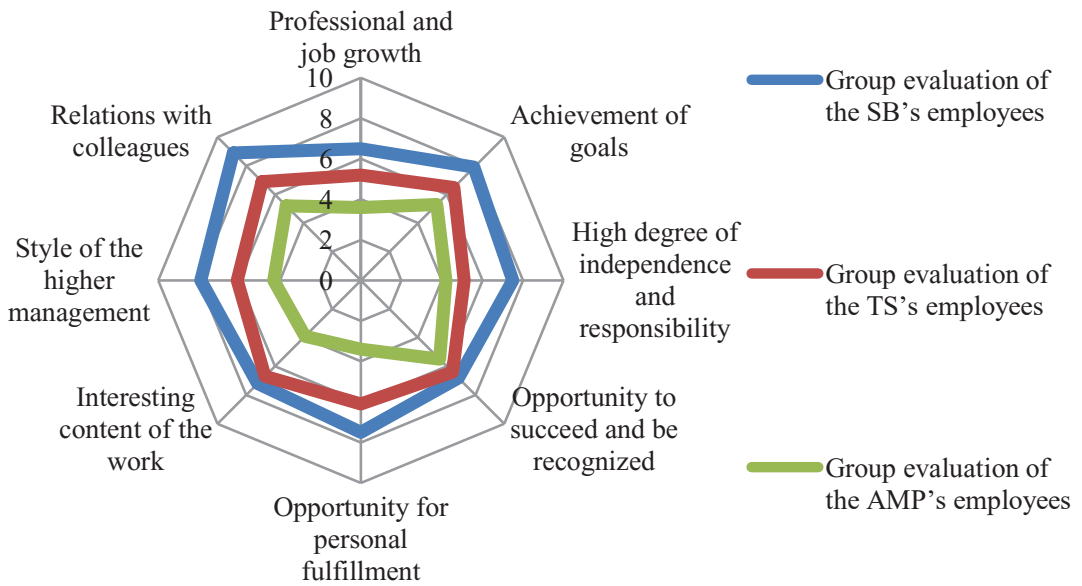

Fig. 3. Wheel of motivational balance of "Fortuna" employees' groups after the implementation of coaching technology.

\section{Conclusions}

The method of assessing motivation by means of the wheel of motivational balance permits to see the motivation of an employee in the form of an octagon, each ray of which displays a separate motivational factor.

The results of the study evaluating the effectiveness of coaching show an improvement in employees' perception of their work, a positive attitude of an employee to work, increased responsibility and autonomy, as well as ease of work and increased satisfaction from work. It can be concluded that coaching tools in the personnel's management have a positive impact on an employee's motivation, forming stable internal motivation and initiative to improve the work process and achieve better results. 
The wheel of the motivational balance is a universal method, since its implementation by means of minor adaptation can be useful for assessing the effectiveness of implementing various impact tools on the quality characteristics of company's employees, as well as for companies of any industry.

\section{References}

1. A. Ageev, B. Kuroedov, Features of applying the methodology of the strategic matrix in forecasting the development of States, 296 (2008)

2. E. Komarov, Measurement of motivation and stimulation of personnel 6, 23-28 (2003)

3. A. Kopytova, Procedia Engineering 165, 1132 (2016) DOI: 10.1016/j.proeng.2016.11.830

4. A. Kopytova, MATEC Web of Conferences 106, 08056 (2017) DOI: 10.1051/matecconf/201710608056

5. V. Lezier, M. Gusarova, A. Kopytova, IOP Conference Series: Earth and Environmental Science 90(1), 012069 (2017) DOI: 10.1088/1755-1315/90/1/012069

6. N. Zhdankin, Personnel motivation. Measurement and analysis, 272 (2010)

7. R. Matthews, General Director. Management of industrial enterprise,4, 116-119 (2008)

8. A. Minnullina, R. Abdrazakov, IOP Conference Series: Earth and Environmental Science 90(1), 012089 (2017) DOI: 10.1088/1755-1315/90/1/012089

9. A. Minnullina, R. Abdrazakov, Advances in Intelligent Systems and Computing 692, 1224-1233 (2018) DOI: 10.1007/978-3-319-70987-1_131

10. A. Whitworth, H. Kimsey-House, F. Sandal, Coactive coaching, 354 (2011)

11. M. Gravit, O. Zybina, A. Vaititckii, A. Kopytova, Advances in Intelligent Systems and Computing 692, 1093-1101 (2018) DOI: 10.1007/978-3-319-70987-1_118

12. N. Zotkina, M. Gusarova, A. Kopytova, Advances in Intelligent Systems and Computing 692, 1204-1213 (2018) DOI: 10.1007/978-3-319-70987-1_129

13. N. Zotkina, S. Bardasov, M. Gusarova, A. Kopytova, MATEC Web of Conferences 106, 08050 (2017) DOI: 10.1051/matecconf/201710608050

14. A.V. Kopytova, Exchange of intellectual property 3 (XIV), 31-37 (2015)

15. A. Minnullina, MATEC Web of Conferences 106, 08067 (2017) DOI: $10.1051 /$ matecconf $/ 201710608067$

16. I. Zaychenko, S. Gutman, O. Kalinina Advances in Intelligent Systems and Computing, 692, 453-462 (2018) DOi - 10.1007/978-3-319-70987-1_48

17. I. V. Ilin, A.I. Levina, O. Iliashenko MATEC Web of Conferences, 86, (2016) 05028 DOi - 10.1051/matecconf $/ 20168605028$

18. I. V. Ilin, A. Lepekhin, A.I. Levina, O Yu. Iliashenko, Advances in Intelligent Systems and Computing, 692, 1306-1314 (2018) DOi -10.1007/978-3-319-70987-1_138

19. I. V. Ilin, A.I. Levina, O Yu. Iliashenko, MATEC Web of Conferences, 106, 08066 (2017) DOi-10.1051/matecconf/201710608066 